\title{
A study of polar ozone depletion based on sequential assimilation of satellite data from the ENVISAT/MIPAS and Odin/SMR instruments
}

\author{
J. D. Rösevall, D. P. Murtagh, J. Urban, and A. K. Jones \\ Department of Radio \& Space Science, Chalmers Univ. of Technology, Göteborg, Sweden \\ Received: 3 July 2006 - Published in Atmos. Chem. Phys. Discuss.: 10 October 2006 \\ Revised: 14 December 2006 - Accepted: 12 February 2007 - Published: 16 February 2007
}

\begin{abstract}
The objective of this study is to demonstrate how polar ozone depletion can be mapped and quantified by assimilating ozone data from satellites into the wind driven transport model DIAMOND, (Dynamical Isentropic Assimilation Model for OdiN Data). By assimilating a large set of satellite data into a transport model, ozone fields can be built up that are less noisy than the individual satellite ozone profiles. The transported fields can subsequently be compared to later sets of incoming satellite data so that the rates and geographical distribution of ozone depletion can be determined. By tracing the amounts of solar irradiation received by different air parcels in a transport model it is furthermore possible to study the photolytic reactions that destroy ozone.
\end{abstract}

In this study, destruction of ozone that took place in the Antarctic winter of 2003 and in the Arctic winter of 2002/2003 have been examined by assimilating ozone data from the ENVISAT/MIPAS and Odin/SMR satelliteinstruments. Large scale depletion of ozone was observed in the Antarctic polar vortex of 2003 when sunlight returned after the polar night. By mid October ENVISAT/MIPAS data indicate vortex ozone depletion in the ranges $80-100 \%$ and $70-90 \%$ on the 425 and $475 \mathrm{~K}$ potential temperature levels respectively while the Odin/SMR data indicates depletion in the ranges $70-90 \%$ and $50-70 \%$. The discrepancy between the two instruments has been attributed to systematic errors in the Odin/SMR data.

Assimilated fields of ENVISAT/MIPAS data indicate ozone depletion in the range $10-20 \%$ on the $475 \mathrm{~K}$ potential temperature level, $(\sim 19 \mathrm{~km}$ altitude), in the central regions of the 2002/2003 Arctic polar vortex. Assimilated fields of Odin/SMR data on the other hand indicate ozone depletion in the range $20-30 \%$.

Correspondence to: J. D. Rösevall

(rosevall@ rss.chalmers.se)

\section{Introduction}

For more than two decades massive photochemical depletion of ozone has been observed each spring below $\sim 22 \mathrm{~km}$ altitude in the Antarctic polar vortex (Farman et al., 1985). Indications of corresponding, albeit smaller depletion of ozone in the Arctic spring have also been found (Rex et al., 1998; Newman et al., 2002). The standard explanation for these phenomena involves activation of chlorine reservoir species in heterogeneous reactions that take place on aerosol-particle surfaces in so called polar stratospheric clouds. Polar stratospheric clouds consist of both crystalline and liquid aerosols of nitric- and sulphuric-acid that form inside the polar vortex during the polar winter night. Since it is less stable and therefore warmer, far fewer polar stratospheric clouds however form in the Arctic polar vortex than in its Antarctic counterpart.

When sunlight returns to the polar region after the winter, ozone is lost in photochemical reactions driven by catalyst species such as $\mathrm{Cl}_{\mathrm{x}}, \mathrm{NO}_{\mathrm{x}}$ and $\mathrm{HO}_{\mathrm{x}}$. Ozone losses that occur above $25 \mathrm{~km}$ in the Arctic and Antarctic regions are mainly caused by $\mathrm{NO}_{\mathrm{x}}$. The near total depletion of ozone that occur in the Antarctic polar vortex below $\sim 22 \mathrm{~km}$ altitude is however predominately caused by $\mathrm{Cl}_{\mathrm{X}}$ built up during the winter (Solomon, 1999). Ozone losses driven by $\mathrm{Cl}_{\mathrm{x}}$ are on the other hand much smaller in the Arctic vortex and occur mainly after colder than average winters.

To measure how much ozone is destroyed one must follow air parcels that move in the stratosphere so they can be sampled at consecutive times. The so called Match technique is a lagrangian approach to this problem (Rex et al., 1998). It involves calculating three dimensional trajectories of air parcels that undergo wind driven advection on isentropic surfaces and vertical transport due to radiative cooling of the winter stratosphere. Ozone destruction in the air parcels is subsequently estimated by comparing balloon sonde measurements at the start and at the end of the

Published by Copernicus GmbH on behalf of the European Geosciences Union. 


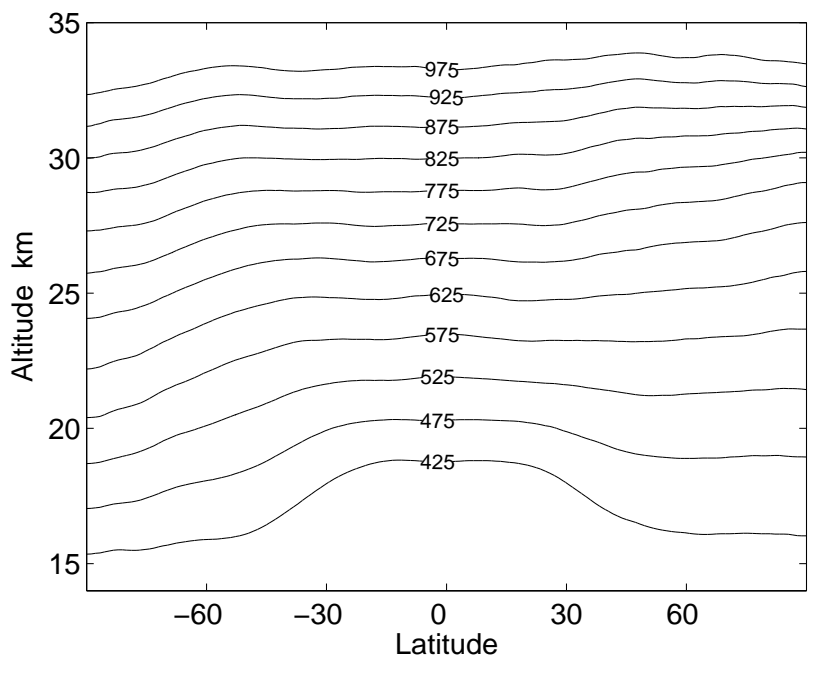

Fig. 1. Average December altitudes of the isentropic levels used in the DIAMOND model. Potential temperatures in Kelvin.

calculated trajectories. It should be possible to use this technique also with satellite data but individual satellite measurements are by and large more noisy which makes the method more difficult to implement. Ozone depletion is instead often estimated by taking daily averages of all satellite measurements inside the polar vortex. To keep track of the polar vortex which moves, changes its shape and sinks during the winter, stratospheric constituents with low chemical reactivity can be followed (Proffitt et al., 1993). Sampling the entire polar vortex at once does however give a rather low spatial resolution. The temporal and spatial coverage of the Match technique is on the other hand limited by the number of balloon sondes available for analysis.

The objective of this study is to demonstrate how ozone depletion can be mapped and quantified by assimilating ozone data from satellites into a wind driven transport model. By assimilating large sets of satellite data the random noise in the individual satellite ozone profiles is averaged out in the model. The transported fields can subsequently be compared to later sets of incoming satellite data for the purpose of determining the rates and geographical distribution of polar ozone depletion.

In Sect. 2 of this paper we present a low-diffusive transport and assimilation model, DIAMOND, that has been developed to carry out the strategy outlined above. The model has been used for studying destruction of polar ozone in the lower stratosphere by assimilating ozone profiles from the Odin/SMR and ENVISAT/MIPAS satellite-instruments, described in Sect. 3 and Sect. 4. The assimilated ozone fields in the DIAMOND model have been validated by comparison to balloon sonde measurements made at the south pole and at $\mathrm{Ny}$-Ålesund $\left(79^{\circ} \mathrm{N}, 12^{\circ} \mathrm{E}\right)$. Vertical transport in the polar vortex has furthemore been traced by assimilating chemically inert nitrous oxide retrieved by Odin/SMR.
A study of vertical transport in the polar vortex of the Antarctic winter of 2003 is presented in Sect. 5 and a study of ozone depletion during that winter is presented in Sect. 6 . Vertical transport and ozone depletion in the Arctic winter of 2002/2003 is studied in Sect. 7 and Sect. 8 respectively. The ozone depletion estimates found using the DIAMOND model are discussed and compared to other studies in Sect. 9.

\section{The DIAMOND model}

The DIAMOND model, (Dynamical Isentropic Assimilation Model for OdiN Data), has been designed to accomplish lowdispersive off-line wind-driven ozone transport in the lower stratosphere. Horizontal advection has been modeled on 12 separate isentropic surfaces between 425 and $975 \mathrm{~K}$ which correspond roughly to altitudes in the range 15 to $35 \mathrm{~km}$. See Fig. 1. Since potential temperatures in dry air are conserved under adiabatic conditions vertical transport across isentropic layers is generally slow in temperate and polar regions. An exception to near adiabatic conditions occurs however during the polar winter night when there is strong radiative cooling of air masses inside the polar vortex. In this study vertical transport has been monitored by keeping track of chemically stable $\mathrm{N}_{2} \mathrm{O}$ that has been assimilated in parallel with the ozone fields.

The DIAMOND model is used for quantifying polar ozone depletion by subtracting passively transported ozone fields from fields of assimilated satellite data. Chemistry has therefore been omitted from the model. The reactivity of ozone in the polar regions tend furthermore to be rather low at altitudes below $25 \mathrm{~km}$ except when fast photolytic destruction of ozone occurs in air masses that have been heterogenically $\mathrm{ClO}_{\mathrm{x}}$ activated during the winter.

\subsection{Transport model}

The DIAMOND model has been designed for studying the polar regions. Horizontal transport has therefore been modeled on a square grid that is centred over one pole and extends to the equator. See Fig. 2. With a grid like this it has been possible to achieve high spatial resolution without using ultra fine time discretisation which is generally a limiting factor for latitude/longitude grids that have very fine zonal grid spacing near the poles. The simplicity of the grid has also facilitated implementing the advection scheme. The fact that the grid does not provide global coverage is on the other hand a disadvantage but it is tolerable since equatorial air masses need several weeks to reach the regions surrounding the polar vortex. Another obvious disadvantage is that the square shape of the grid is distorted in the equatorial region. By transforming the off-line wind fields to the local nonCartesian coordinate systems one can eliminate transportation errors but the use of a rhomboid grid adds some numerical diffusivity to the transport scheme. The square shape of 
the grid is however well retained over the polar regions where ozone depletion occurs. A grid spacing of $167 \times 167 \mathrm{~km}$ (over the pole) and a time-step of $10 \mathrm{~min}$ length has been used in this study.

Horizontal off-line wind driven advection has been implemented using the Prather transport scheme (Prather, 1986). It is a mass conservative Eulerian type of transport scheme that achieves very low numerical diffusivity by storing and transporting the first and second order spatial derivatives of tracer fields as well as the average tracer concentration in each grid-box. The Prather scheme is thus much more time consuming than a simple upstream transport scheme but the low numerical diffusivity achieved is essential when quantifying ozone depletion processes that proceed over several months. Wind fields obtained from the European Centre for Medium-range Weather Forecasts, ECMWF, have been used to force the advection scheme in this study.

Vertical transport is generally not implemented in the DIAMOND model except when there is substantial radiative cooling of air masses inside the polar vortex during the polar night. The rate of decent of air masses in the vortex is determined by assimilating chemically inert $\mathrm{N}_{2} \mathrm{O}$ and tracing the vortex average concentrations on different model levels. (The decent in the Antarctic vortex of 2003 and the Arctic vortex of 2002/2003 are presented in Sects. 5 and 7 respectively.) The rates of decent obtained are subsequently used to drive vertical transport of ozone inside the vortex. The vertical transport is implemented using one using one simple upstream step per day.

\subsection{Assimilation scheme}

Satellite data are assimilated into the DIAMOND model using a sequential algorithm that can be described as a variant of the familiar Kalman filter. A field containing estimates of the errors in the model is thus built up and transported alongside the ozone field for the purpose of weighting in new data in an optimal way. In each model time-step the assimilation algorithm updates the subset of grid points that are located within $3000 \mathrm{~km}$ of any satellite observations that have been made. New data is weighted in according to the formula below where $\boldsymbol{X}_{\boldsymbol{b}}$ is a column vector containing the subset of model grid-points that are affected by assimilation, $\boldsymbol{X}_{\boldsymbol{a}}$ is the same subset of the model grid after assimilation and $\boldsymbol{Y}$ is a vector containing the satellite data to be assimilated. $\mathbf{H}$ is an operator for linear interpolation from the model grid to the locations of the satellite measurements and $\mathbf{W}$ is an optimal weighting matrix that is derived in each time-step (Daley, 1991).

$X_{a}=X_{b}+\mathbf{W}\left(\boldsymbol{Y}-\mathbf{H}\left(\boldsymbol{X}_{b}\right)\right)$

The optimal weighting matrix, $\mathbf{W}$, is derived using estimates of the noise in the satellite measurements, given in a covari-

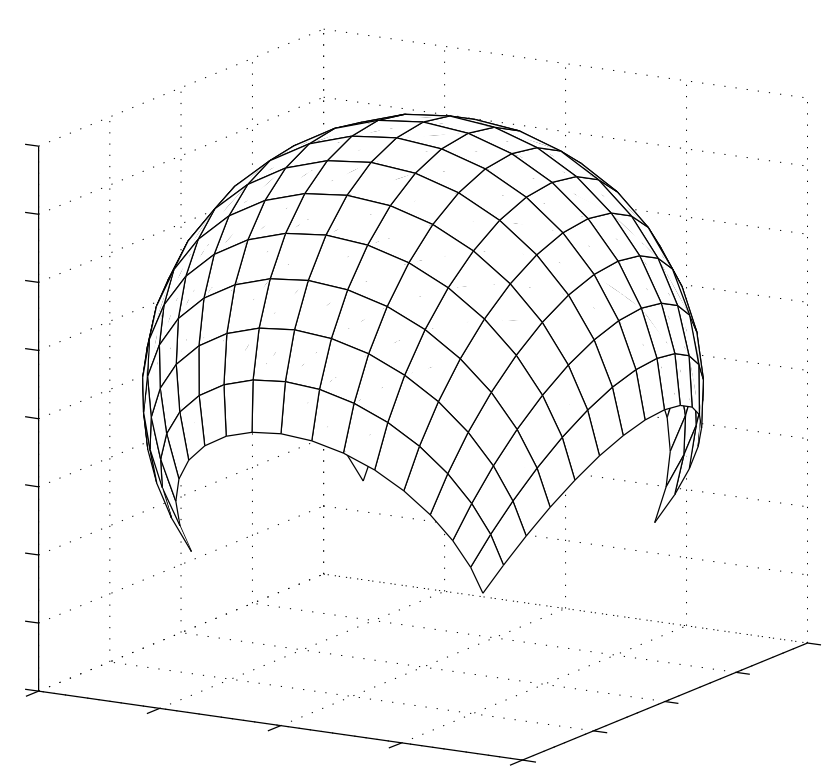

Fig. 2. The shape of the grid used in the DIAMOND model.

ance matrix $\mathbf{R}$, and estimates of the errors in the model field, given by two covariance matrices $\mathbf{S}_{\mathbf{b o}}$ and $\mathbf{S}_{\mathbf{o o}}$.

$\mathbf{W}=\mathbf{S}_{\mathbf{b o}}\left(\mathbf{S}_{\mathbf{o o}}+\mathbf{R}\right)^{-1}$

To be more precise, $\mathbf{S}_{\mathbf{b o}}$ is a cross covariance matrix of the model errors in the vector $\boldsymbol{X}_{\boldsymbol{b}}$ and the model errors at the points of satellite observations, $\mathbf{H}\left(\boldsymbol{X}_{\boldsymbol{b}}\right)$. $\mathbf{S}_{\mathbf{o o}}$ is on the other hand a covariance matrix for the errors in $\mathbf{H}\left(\boldsymbol{X}_{\boldsymbol{b}}\right)$ alone.

$\mathbf{R}=\left\langle\left(\boldsymbol{Y}-\boldsymbol{Y}_{\boldsymbol{t}}\right)\left(\boldsymbol{Y}-\boldsymbol{Y}_{\boldsymbol{t}}\right)^{T}\right\rangle$

$\mathbf{S}_{\mathrm{bo}}=\left\langle\left(\boldsymbol{X}_{\boldsymbol{b}}-\boldsymbol{X}_{\boldsymbol{t}}\right)\left(\mathbf{H}\left(\boldsymbol{X}_{\boldsymbol{b}}\right)-\mathbf{H}\left(\boldsymbol{X}_{\boldsymbol{t}}\right)\right)^{T}\right\rangle$

$\mathbf{S}_{\mathbf{o o}}=\left\langle\left(\mathbf{H}\left(\boldsymbol{X}_{\boldsymbol{b}}\right)-\mathbf{H}\left(\boldsymbol{X}_{\boldsymbol{t}}\right)\right)\left(\mathbf{H}\left(\boldsymbol{X}_{\boldsymbol{b}}\right)-\mathbf{H}\left(\boldsymbol{X}_{\boldsymbol{t}}\right)\right)^{T}\right\rangle$

$\boldsymbol{X}_{\boldsymbol{t}}$ and $\boldsymbol{Y}_{\boldsymbol{t}}$ in the formulae above denote the true atmospheric concentrations of the tracer at the grid-points and at the points of satellite observations respectively and \langle\rangle denotes the operator for expectation values.

To derive $\mathbf{W}$ it is thus necessary to estimate the matrixes $\mathbf{S}_{\text {bo }}$ and $\mathbf{S}_{\mathbf{o o}}$. A computationally efficient solution to this problem can be implemented by estimating the correlation between different points in the model, (indexed $i$ and $j$ ), with an empirical correlation function $F(i, j)$ so that only $\sigma_{i}$, (the estimated error standard deviations in the actual grid points), have to be stored and transported (Menard et al., 2000).

$\mathbf{S}_{i j}=\sigma_{i} \sigma_{j} * F(i, j)$

The correlation function, $F(i, j)$, must be chosen empirically to fit the particular transport model that it is used with. 


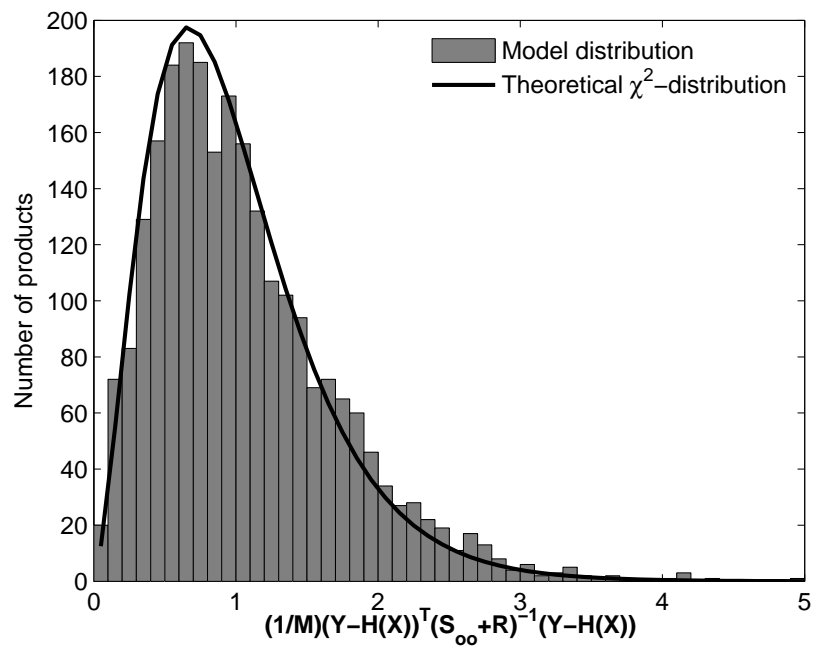

Fig. 3. The correlation distance parameter $L$ has been tuned to a value for which the distribution of the dimensionless quadratic form $(\boldsymbol{Y}-\mathbf{H}(X))^{T}\left(\mathbf{S}_{\mathbf{o o}}+\mathbf{R}\right)^{-1}(\boldsymbol{Y}-\mathbf{H}(X))$ fits a theoretical $\chi^{2}$ distribution.

One way to simplify this process is to assume that $F(i, j)$ is a function of the geographical distance, $r_{i j}$, between the two grid points $i$ and $j$. This methodology has for example been described in (Khattatov et al., 2000) where several different function types were evaluated as candidates for $F\left(r_{i j}\right)$. One function that they found favourable was the Gaussian shaped function. It has therefore been used in the Diamond model.

$F(i, j)=\exp \left(-\frac{r_{i j}^{2}}{2 L^{2}}\right)$

The Gaussian function is fitted to the model by adjusting the parameter $L$ to a value where empirical agreement is reached between $F\left(r_{i j}\right)$ and error correlations observed in the model.

Assimilation of new data is obviously a process that lowers the error standard deviation estimates in the $\sigma$ field. Consequently Kalman filtering theory describes how the field should be updated when assimilation has occurred.

$\boldsymbol{\sigma}_{\boldsymbol{a}}^{2}=\boldsymbol{\sigma}_{\boldsymbol{b}}^{2}-\operatorname{diag}\left(\mathbf{W} \mathbf{S}_{\mathbf{b o}}^{T}\right)$

There are on the other hand also factors like chemical processes in the stratosphere and imperfections in the transport scheme that makes it necessary to add a growth term to the $\sigma$ field. In the DIAMOND model, linear increment with time has been used to approximate the growth of uncertainty in the tracer fields.

$\sigma_{(t+\Delta t)}=\sigma_{t}+k_{\sigma} * \Delta t$

Both $L$ and $k_{\sigma}$ are parameters that must be tuned empirically. Ideally they should be set to values that minimise the
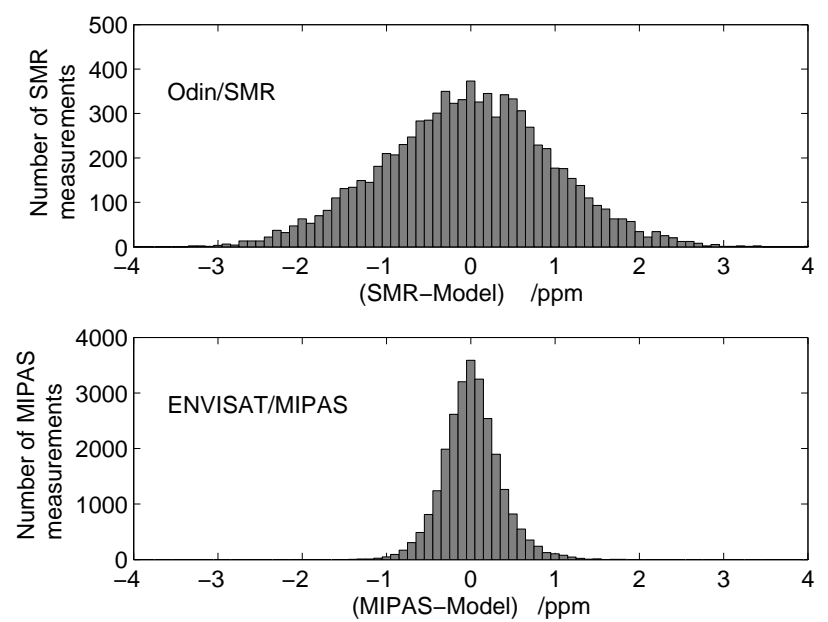

Fig. 4. Observations minus model background on the $475 \mathrm{~K}$ potential temperature level. All observations included in the histograms were made north of $30^{\circ} \mathrm{N}$ during January, February and March of 2003.

difference between model forecasts, $\mathbf{H}_{n}(X)$, and individual satellite observations, $y_{n}$, in a least squares sense.

$\sum_{n=1}^{N}\left(y_{n}-\mathbf{H}_{n}(X)\right)^{2} / N$

This least squares value is however not very sensitive to either $L$ or $k_{\sigma}$ once the assimilation model has run for a few days. The error growth rates, $k_{\sigma}$, on the different model levels has therefore been set to values for which agreement is achieved between the model error standard deviation estimates, $\sigma_{x}$, and the observed variance between model and satellite observations.

$L$ has on the other hand been derived by evaluating the quadratic form in expression (11) below. The dimensionless values given by the expression are expected to be distributed according to the so called $\chi^{2}$-function of order equal to $M$ (the number of elements in $\boldsymbol{Y}$ ) if the matrices $\mathbf{R}$ and $\mathbf{S}_{\mathbf{0 o}}$ provide correct estimates of the error covariances for the vectors $\boldsymbol{Y}$ and $\boldsymbol{H}(\boldsymbol{X})$ respectively. $\mathbf{R}$ is not controlled by any assimilation parameter since it is supplied in the satellite data. The non diagonal elements in $\mathbf{S}_{\mathbf{0 o}}$ are on the other hand functions of $L$. The parameter has thus been tuned to the value $920 \mathrm{~km}$ for which the expected $\chi^{2}$-distribution was found, (see Fig. 3).

$$
(\boldsymbol{Y}-\mathbf{H}(X))^{T}\left(\mathbf{S}_{\mathbf{o o}}+\mathbf{R}\right)^{-1}(\boldsymbol{Y}-\mathbf{H}(X)) \sim \chi_{M}^{2}
$$

\section{Odin/SMR}

The Odin satellite, launched in 2001 as a joint venture by the national space agencies of Sweden, Canada, Finland and 

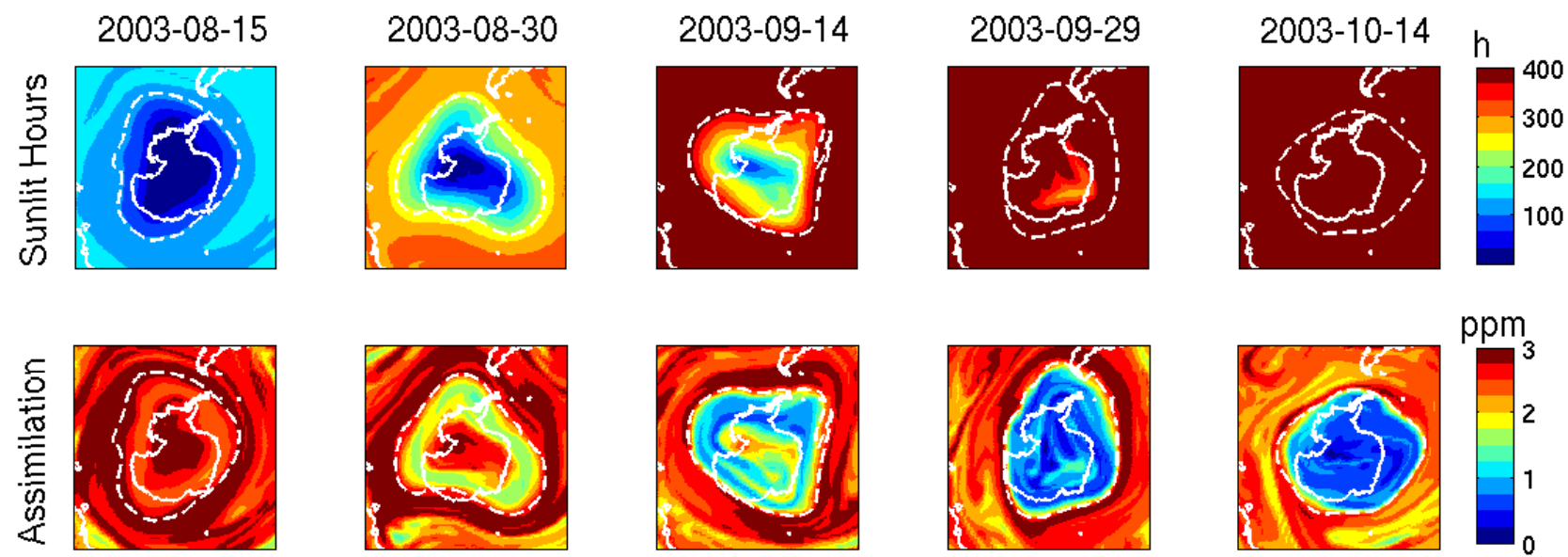

ppm
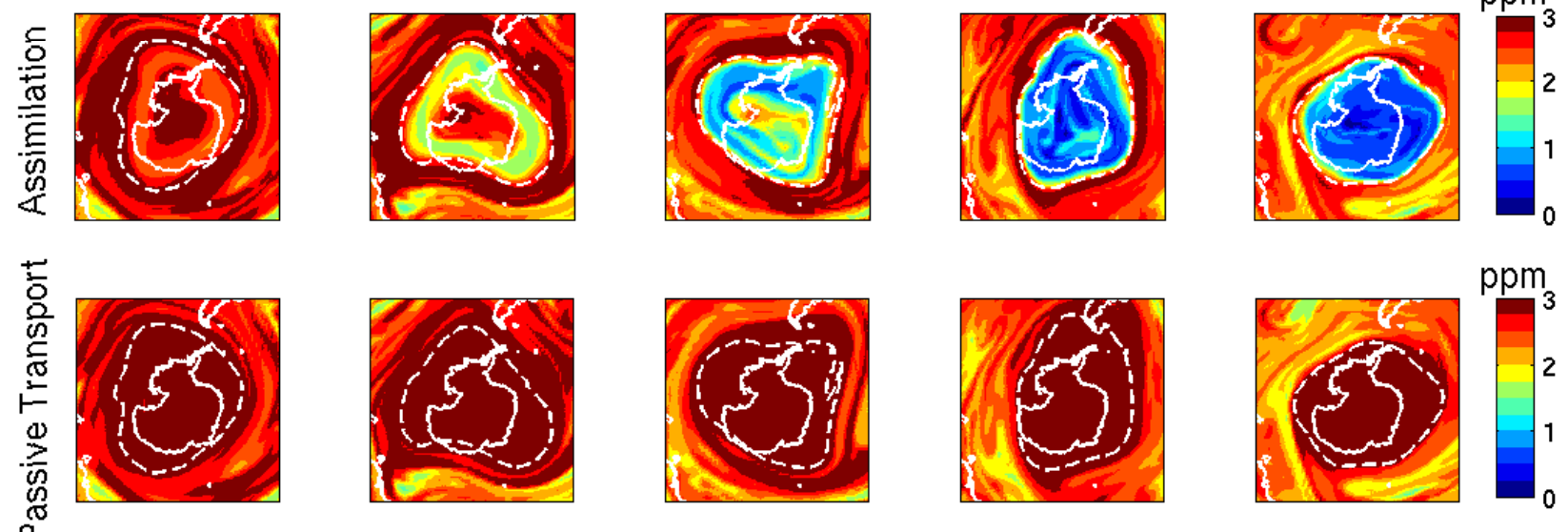

Fig. 5. Assimilated fields of ozone on the $475 \mathrm{~K}$ potential temperature level compared to fields passively transported from 1 August of 2003. The fields in the top row represent the number of hours of sunlight that has fallen on the air masses in the model since 1 August, the middle row contains assimilated fields of ozone profiles from ENVISAT/MIPAS and the bottom row contains fields passively transported from 1 August without any new data assimilated into them. The dashed lines outline the border of the polar vortex.

France, completes $\sim 15$ near-terminator polar orbits per day with descending nodes at 06:00 $\mathrm{h}$ local solar time. Its payload consists of two different limb scanning instruments, SMR (Sub-Millimetre Radiometer) and OSIRIS (Optical Spectrograph/InfraRed Imaging System), that obtain vertical profiles of ozone and other trace species in the middle atmosphere (Murtagh et al., 2002). The SMR instrument is however also used for radio-astronomy which means that $50 \%$ of the satellites operational time is used for astrophysics instead of Earth observations.

The OSIRIS instrument detects visible and infrared light scattered from the sun. It can therefore not make observations when the sun is below the horizon of the satellite in the winter hemisphere. Consequently no data from the OSIRIS instrument has been used in this study.

The SMR instrument comprises four tunable Schottkydiode single-sideband heterodyne microwave receivers. In the basic mode for stratospheric observations, two of the receivers covering the $486-504 \mathrm{GHz}$ and $541-558 \mathrm{GHz}$ frequency bands respectively, are used to detect microwave emission lines in the spectra of $\mathrm{O}_{3}, \mathrm{~N}_{2} \mathrm{O}, \mathrm{ClO}$ and $\mathrm{HNO}_{3}$. Two separate lines, centred at $501.5 \mathrm{GHz}$ and $544.9 \mathrm{GHz}$ respectively, are observed in the spectrum of ozone. The ozone data used in this study have been retrieved from the $\mathbf{5 0 1 . 5}$
GHz line using the Chalmers-v2.0 retrieval scheme. The random noise standard deviation in the individual ozone profiles is below $1.5 \mathrm{ppmv}$ and the estimated systematic errors are less than 0.75 ppmv (Urban et al., 2006, 2005). In the polar regions the ozone profiles thus obtained cover altitudes in the range $12-50 \mathrm{~km}$ with $\sim 3 \mathrm{~km}$ altitude resolution. The $\mathrm{N}_{2} \mathrm{O}$ data used in this study have been retrieved from a line at $502.3 \mathrm{GHz}$ using the same software. The $\mathrm{N}_{2} \mathrm{O}$ profiles cover altitudes in the range $12-60 \mathrm{~km}$ with $\sim 1.5 \mathrm{~km}$ altitude resolution. The noise in the individual $\mathrm{N}_{2} \mathrm{O}$ profiles is below $30 \mathrm{ppbv}$ and the estimated systematic errors are less than 12 ppbv (Urban et al., 2006, 2005).

\section{ENVISAT/MIPAS}

The ENVISAT satellite, launched in 2002 by the European Space Agency (ESA), completes $\sim 15$ polar orbits per day with descending nodes at 10:00 $\mathrm{h}$ local solar time. Its mission comprises monitoring the land, ice, oceans and atmosphere of the Earth providing data for environmental research. Ten different instruments are included in its payload, three of which GOMOS, MIPAS and SCIAMACHY were designed to study trace gases in the atmosphere. 

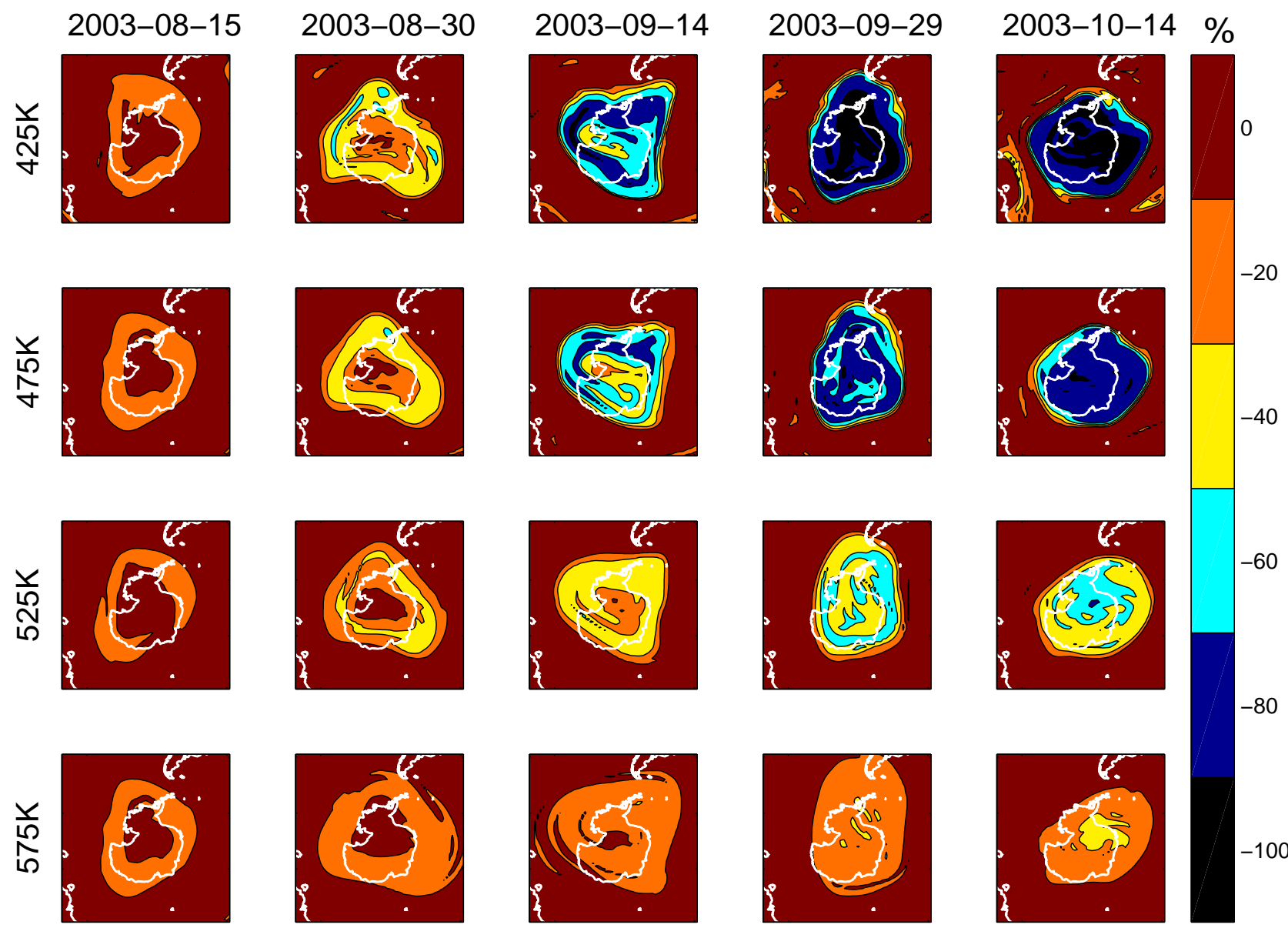

Fig. 6. Estimates of ozone depletion in the 2003 Antarctic spring made by comparing assimilated fields of ENVISAT/MIPAS data to fields passively transported from 1 August. The percentages displayed were calculated using the formula: $100 \times[($ active field $)-$ passive field)]/(passive field).

The MIPAS instrument, (Michelson Interferometer for Passive Atmospheric Sounding), is a passive limb scanning high-resolution Fourier transform spectrometer for the middle infrared region. The instrument is primarily designed to retrieve atmospheric profiles of ozone and other atmospheric trace species, including CFC's and the complete $\mathrm{NO}_{\mathrm{y}}$ family, but it can also provide estimates of tropospheric cirrus and stratospheric ice clouds including polar stratospheric clouds (Endemann, 1999). The data retrieval scheme for ozone and other trace gases is described in Ridolfi et al. (2000). The MIPAS ozone profiles used in this report have been produced using the 4.61 version of the retrieval software and cover the altitude range $8-55 \mathrm{~km}$ with $3 \mathrm{~km}$ altitude resolution. The noise level in the individual ozone profiles is below $10 \%$ of the profile volume mixing ratios, (Ridolfi et al., 2000; Raspollini et al., 2006), which typically corresponds to less than 0.5 ppmv below $25 \mathrm{~km}$ altitude in the stratosphere.
The distribution of MIPAS ozone observations minus DIAMOND model forecasts on the $475 \mathrm{~K}$ level is presented in Fig. 4. The distribution of Odin/SMR ozone observations minus DIAMOND model forecasts on the $475 \mathrm{~K}$ level is also presented. One can clearly see that the Odin/SMR ozone data is much more noisy than the data from ENVISAT/MIPAS. (Different scales have been used for the $y$-axes of the two histograms to make it possible to see the random distributions of the two sets of data. It may therefore seem like less data from ENVISAT/MIPAS than from Odin/SMR are included in the figure although the number of ozone profiles from ENVISAT/MIPAS is more than twice the number of Odin/SMR profiles.) 

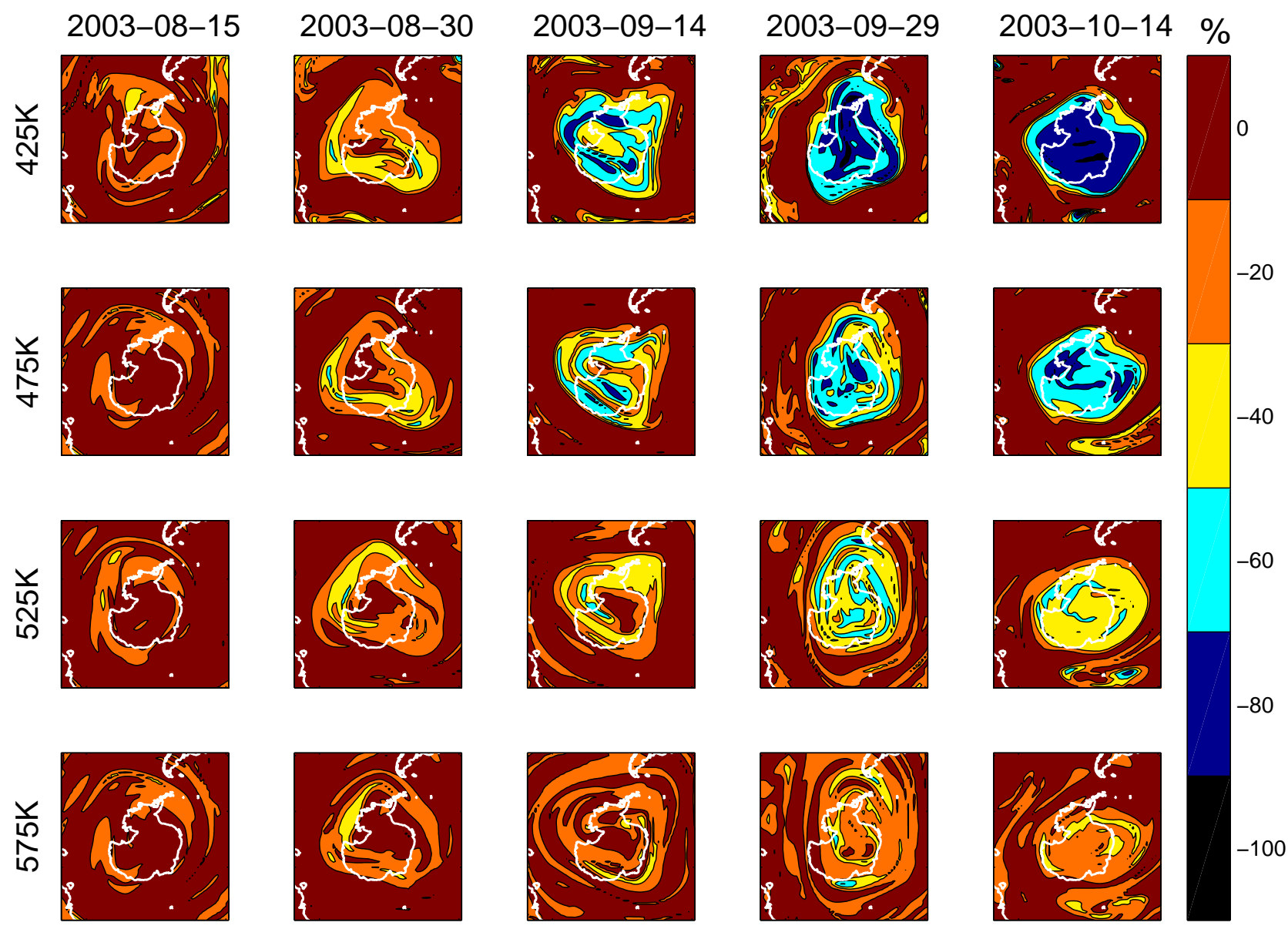

Fig. 7. Estimates of ozone depletion in the 2003 Antarctic spring made by comparing assimilated fields of Odin/SMR data to fields passively transported from 1 August. The percentages displayed were calculated using the formula: $100 \times[($ active field)-(passive field)]/(passive field).

\section{Vertical transport in the Antarctic polar vortex of 2003}

$\mathrm{N}_{2} \mathrm{O}$ data from Odin/SMR have been assimilated in the DIAMOND model to keep track of the vertical transport processes. The mixing ratio of $\mathrm{N}_{2} \mathrm{O}$ decreases rapidly with altitude since the species is destroyed by high energy UVradiation in the upper stratosphere. $\mathrm{N}_{2} \mathrm{O}$ is on the other hand chemically inert at lower altitudes and in the polar night and can therefore be used as a passive tracer to monitor transport in the polar vortex. Time series of model vortex average $\mathrm{N}_{2} \mathrm{O}$ mixing ratios are plotted in Fig. 9. The vortex averages are defined as the average mixing ratio on the 30 million $\mathrm{km}^{2}$ area with lowest $\mathrm{N}_{2} \mathrm{O}$ concentration on each potential temperature level in the DIAMOND model. $\mathrm{N}_{2} \mathrm{O}$ samples of equal size have thus been obtained on all levels in the vortex which makes the sample averages relevant for tracing vertical transport in it. Using samples with constant size throughout the months studied is furthermore a consistent way of defining the polar vortex. The 30 million $\mathrm{km}^{2}$ samples are how- ever well retained within the vortex borders as defined by the contours of maximum gradient in the $\mathrm{N}_{2} \mathrm{O}$ fields.

The $\mathrm{N}_{2} \mathrm{O}$ mixing ratios in Fig. 9 decrease rapidly from May to late July, indicating fast radiative cooling of the polar vortex during this period. From early August to late October the mixing ratios were on the other hand more stable which indicates that transport between different potential temperature levels was slow. By following the vortex average $\mathrm{N}_{2} \mathrm{O}$ mixing ratios we estimate that the potential temperatures on all four levels described in Fig. 9 decreased by $\sim 10 \mathrm{~K}$ during August and remained stable in September and October. Vertical transport thus had a small impact on the ozone mixing ratios in the vortex during these months since the potential temperature difference between model levels is $50 \mathrm{~K}$ and the ozone mixing ratios in the polar vortex generally differ with $10-20 \%$ between model levels. 

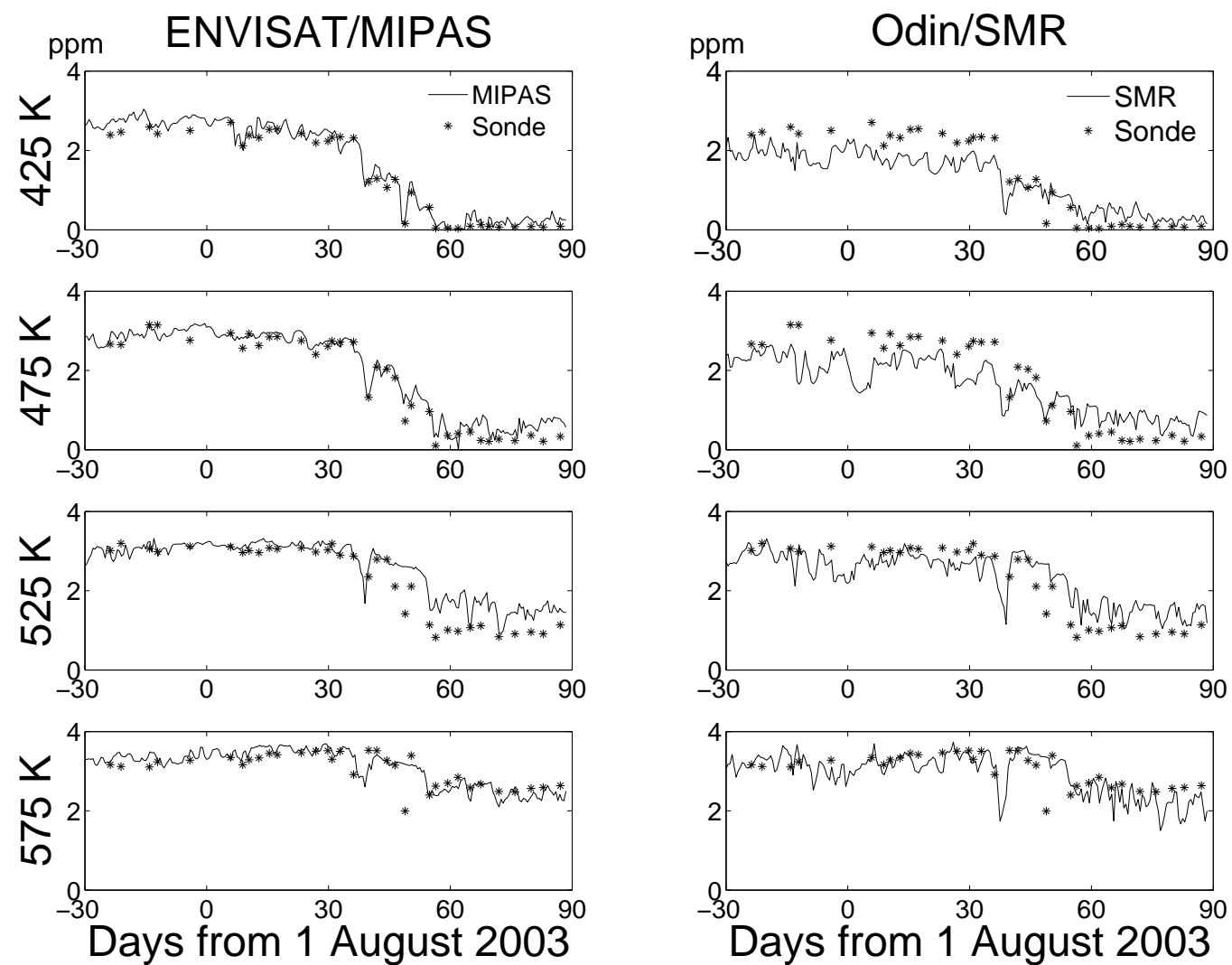

Fig. 8. Assimilated satellite data compared to balloon sonde measurements made over the south pole during the Antarctic winter of 2003. The solid lines represent the ozone mixing ratios found directly over the south pole in the DIAMOND model and the stars represent sonde measurements made at the same location. The sonde data has been obtained from the Network for the Detection of Atmospheric Composition Change (NDACC) and is publicly available (see http://www.ndacc.org).

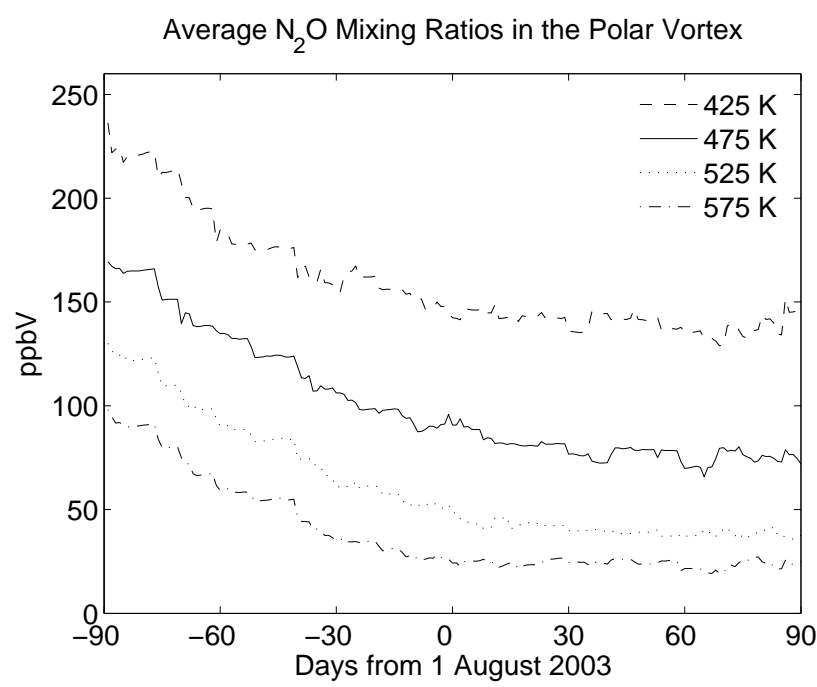

Fig. 9. Time evolution of the average $\mathrm{N}_{2} \mathrm{O}$ mixing ratios on different potential temperature levels in the Antarctic polar vortex of 2003. The vortex averages have been obtained from assimilated fields of Odin/SMR $\mathrm{N}_{2} \mathrm{O}$ data.

\section{Ozone depletion in the Antarctic Winter of 2003}

The ozone destruction that occurred in the Antarctic polar vortex of 2003 has been studied by comparing assimilated fields of ozone to ozone fields that have been passively transported from 1 August of that year. To avoid issues associated with spin-up of the model the initial ozone fields were obtained by assimilating ozone profiles into the DIAMOND model for more than two months prior to 1 August. Vertical transport was not implemented in the Diamond model after 1 August since assimilated $\mathrm{N}_{2} \mathrm{O}$ fields indicated little such transport (see Sect. 5).

The time evolution on the $475 \mathrm{~K}$ potential temperature level can be seen in Fig. 5. The top fields in the figure represent the hours of sunlight that had fallen on the air masses in the model since 1 August. The middle row contains assimilated fields of ozone profiles from ENVISAT/MIPAS and the bottom row contains fields passively transported from 1 August without any new data assimilated into them. The initial ozone fields were obtained by assimilating ozone profiles into the DIAMOND model for more than two months prior to 1 August. Substantial depletion of ozone can be seen in 

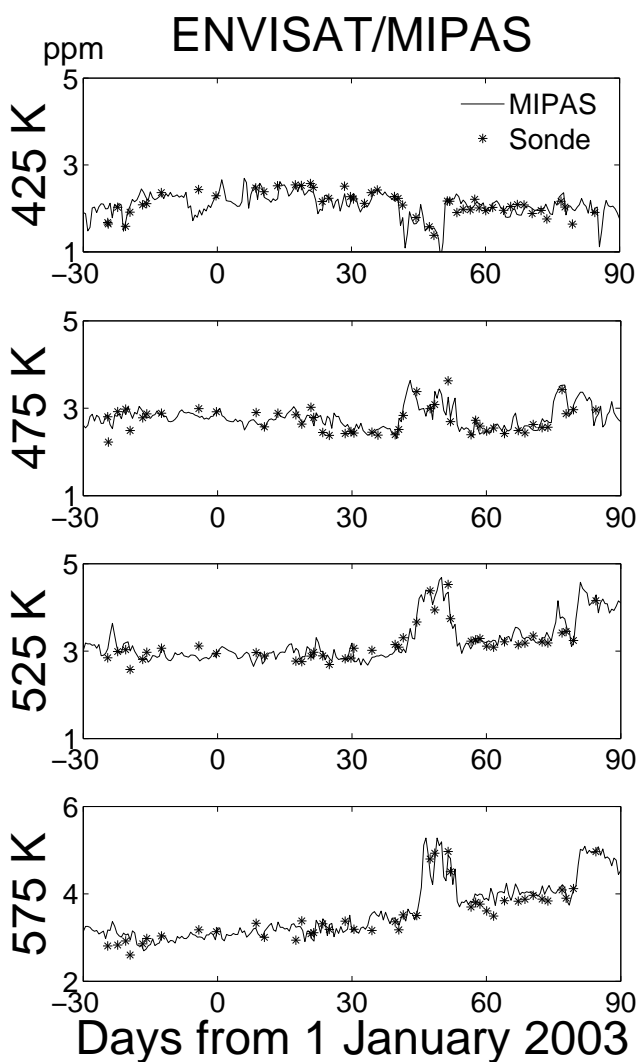
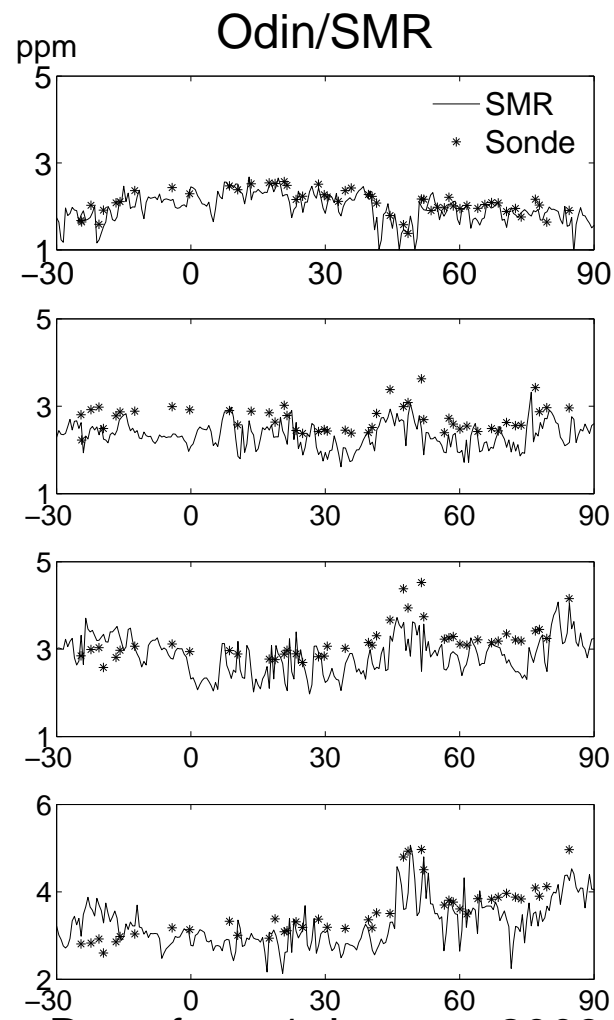

Days from 1 January 2003

Fig. 10. Assimilated satellite data compared to balloon sonde measurements made over $\mathrm{Ny}$-Ålesund $\left(79^{\circ} \mathrm{N}, 12^{\circ} \mathrm{E}\right)$ during the Arctic winter of 2002/2003. Same source of sonde data as in Fig. 8 .

the polar vortex as the air masses become exposed to sunlight. Large scale ozone destruction thus occurs first at the outer edges of the vortex in August and reaches the central polar vortex by the end of September.

Quantitative estimates of the 2003 Antarctic ozone depletion have been made using assimilated fields of ozone data from ENVISAT/MIPAS and Odin/SMR. See Figs. 6 and 7 respectively. Both sets indicate that ozone destruction started at the outer edges of the polar vortex in August and spread to the central vortex by mid September. The Odin/SMR fields however indicate significantly less depletion than the ENVISAT/MIPAS fields on the 425 and $475 \mathrm{~K}$ potential temperature levels. By mid October the ENVISAT/MIPAS data indicate ozone depletion in the ranges $80-100 \%$ and $70-90 \%$ on the 425 and $475 \mathrm{~K}$ levels respectively while the Odin/SMR data indicates depletion in the ranges 70-90\% and 50-70\%.

An obvious prerequisite for obtaining correct estimates of polar ozone depletion using the method presented above is that the satellite instruments used to collect the ozone data detects all ozone depletion that occurs in a quantitatively correct manner. Constant systematic errors in the satellite data can be tolerated but they must not change over the time period that is studied.
The assimilated fields obtained from ENVISAT/MIPAS and Odin/SMR data have been compared to balloon sonde measurements in Fig. 8. The stars represent balloon sonde measurements made at the south pole and the solid lines represent the ozone concentrations found in the DIAMOND assimilation model over the same location. One can see that the assimilated fields of ENVISAT/MIPAS data agree fairly well to the balloon sondes except on the $525 \mathrm{~K}$ level from late September throughout October when the assimilated fields give ozone concentrations that are roughly $1 \mathrm{ppm}$ higher than the sonde measurements. Otherwise the concentrations in the assimilated fields of ENVISAT/MIPAS data generally stay within $0.25 \mathrm{ppm}$ of the sondes. (A separate paper is currently under preparation in which the assimilation model is used for validating MIPAS data.)

The assimilated fields obtained using Odin/SMR data do on the other hand not agree well with the sonde measurements on the 425,475 and $525 \mathrm{~K}$ potential temperature levels. The assimilated ozone concentrations are too low before large scale depletion occurs and too high after the ozone hole has formed. Estimates of ozone depletion made using this set of data will thus underestimate the ozone depletion. These biases are currently under investigation by the Odin/SMR science team at the Chalmers University of Technology. 


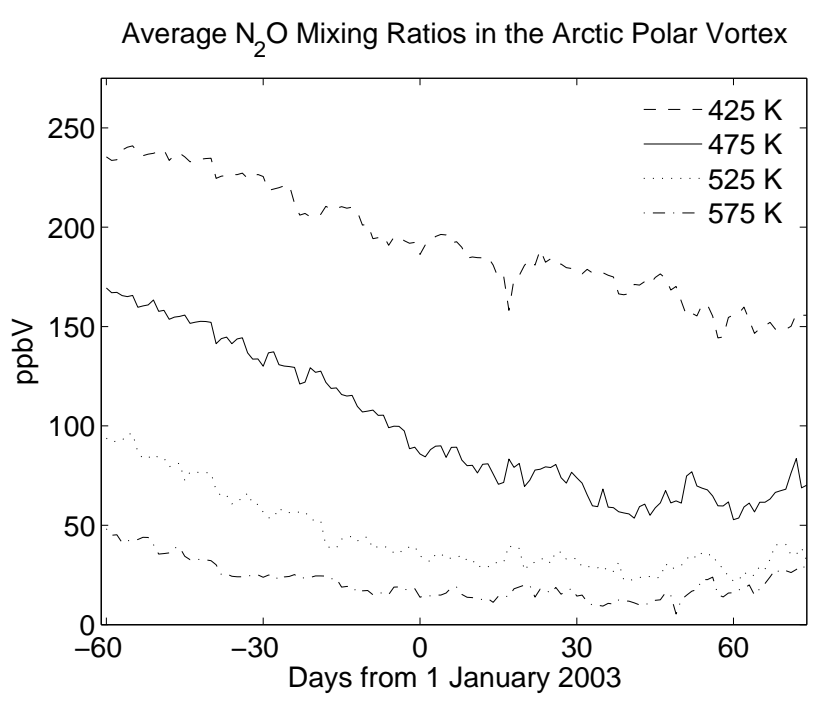

Fig. 11. Time evolution of the average $\mathrm{N}_{2} \mathrm{O}$ mixing ratios on different potential temperature levels in the Arctic polar vortex of $2002 / 2003$. The vortex averages have been obtained from assimilated fields of Odin/SMR $\mathrm{N}_{2} \mathrm{O}$ data.

\section{Vertical transport in the Arctic polar vortex of 2002/2003}

The time evolution of vortex average $\mathrm{N}_{2} \mathrm{O}$ mixing ratios in the Arctic winter of 2002/2003 are presented in Fig. 11. Substantial vertical transport across the model potential temperature levels are indicated by the falling mixing ratios. We estimate that the potential temperatures of air masses fell by $\sim 1 \mathrm{~K}$ per day in November and December and by $\sim 0.7 \mathrm{~K}$ per day in January and early February. The ozone mixing ratios in the vortex increased therefore during the same period due to vertical transport of more ozone rich air masses from higher altitudes. Due to this effect vertical transport has been implemented in the DIAMOND transport model when used to estimate ozone depletion in the Arctic polar vortex of 2002/2003.

\section{Ozone depletion in the Arctic Winter of 2002/2003}

Temperatures in the 2002/2003 Arctic polar vortex were low enough to sustain polar stratospheric clouds from mid November to mid January leading to $15-30 \%$ activation of chlorine reservoir species in January and February (EORCU, 2003). $\mathrm{ClO}_{\mathrm{x}}$ catalyzed photochemical destruction of ozone was therefore possible in sunlit areas of the vortex.

Assimilated fields of ENVISAT/MIPAS and Odin/SMR data have been compared to ozone sonde measurements made at Ny-Ålesund $\left(79^{\circ} \mathrm{N}, 12^{\circ} \mathrm{E}\right)$, see Fig. 10 . The ENVISAT/MIPAS fields agree well to the sonde data while discrepancies can be seen between the sondes and the
Odin/SMR fields. Neither sonde nor satellite data however show any clear signs of ozone depletion. (Ny-Ålesund was located outside the polar vortex for a 10 day period in the latter half of February causing low ozone mixing ratios on the $425 \mathrm{~K}$ potential temperature level and elevated mixing ratios on the levels above during this period.)

Ozone depletion occurring in the Arctic polar vortex after 1 January 2003 have furthermore been studied using the methodology outlined in Sect. 6. The time evolution on the $475 \mathrm{~K}$ potential temperature level is presented in Fig. 12. Row (A) in the figure describes the number of sunlit hours from 1 January, row (B) describes the temperatures on the respective days and the white lines outline the polar vortex border defined as the contour of maximum gradient in the assimilated $\mathrm{N}_{2} \mathrm{O}$ fields. Rows (C) and (D) describe ozone depletion derived using ENVISAT/MIPAS data and rows (E) and $(\mathrm{F})$ describe ozone depletion derived using Odin/SMR data. Vertical transport at a rate of $0.7 \mathrm{~K}$ per day was implemented in the vortex during January and the first 10 days of February when deriving rows $(\mathrm{C})$ and $(\mathrm{E})$ while no vertical transport was implemented when deriving rows $(\mathrm{D})$ and $(\mathrm{F})$. By including vertical transport in the passive transport model we observe $\sim 5 \%$ additional ozone destruction compared to when vertical transport is not implemented.

The ENVISAT/MIPAS fields in rows (C) and (D) indicate 10-20\% ozone destruction in the central polar vortex by the end of January. The fields do on the other hand not indicate any significant destruction of ozone near the outer edges of the vortex which is unlike the pattern observed in the southern hemisphere where large-scale destruction of ozone begins at the vortex outer edges before it reaches the vortex centre. One plausible explanation for the difference is that large scale chlorine activation only occurred in the colder central regions of the 2002/2003 Arctic polar vortex.

The Odin/SMR fields in rows (E) and (F) indicate 20$30 \%$ ozone depletion in the central vortex by the end of January. The areas affected by ozone destruction subsequently grow until mid February after which large scale mixing occur across the vortex border masking the effect of the preceding ozone destruction.

\section{Conclusions}

In this study we have demonstrated how the DIAMOND transport and assimilation model can be used to map and quantify Antarctic as well as Arctic polar ozone depletion. The ozone destruction observed in the Antarctic polar vortex of 2003 was spatially confined to regions where sunlight had returned after the polar night. Large scale ozone depletion thus started at the outer edges of the vortex in August and reached the central region by mid september. The ozone destruction found in the Arctic winter of 2002/2003 was on the other hand mainly confined to the central regions of the vortex. 

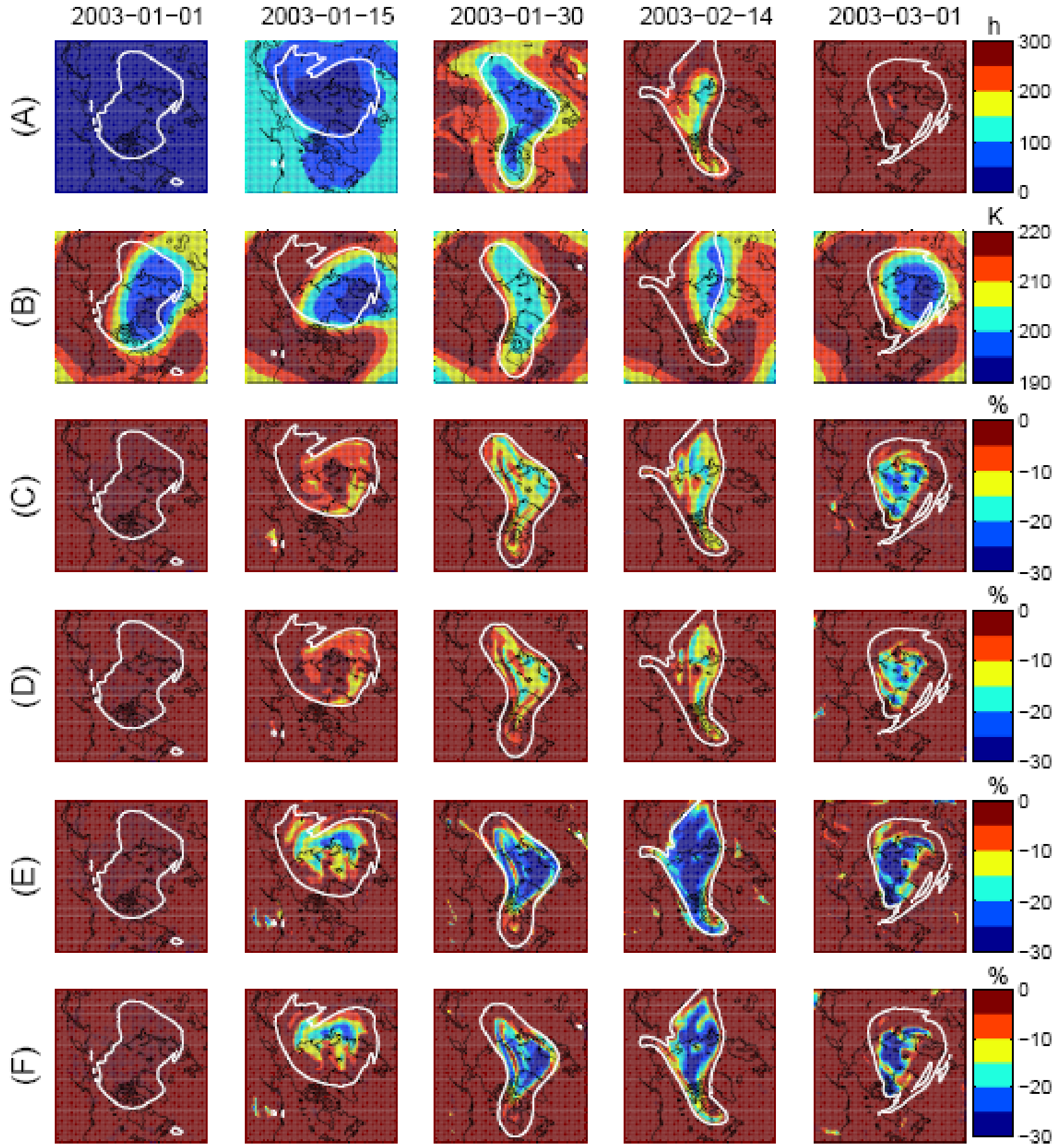

Fig. 12. A study of Arctic ozone depletion on the $475 \mathrm{~K}$ potential temperature level during the winter of 2002/2003 made by comparing assimilated fields of ENVISAT/MIPAS and Odin/SMR ozone data to fields passively transported from 1 January. The percentages displayed were calculated using the formula: $100 \times[$ (active field)-(passive field)]/(passive field). Row (A) describes the number of hours of sunlight that has fallen on the air masses in the model since 1 January. Row (B) describes the temperatures on the $475 \mathrm{~K}$ potential temperature level. Rows (C) and (D) describe estimates of ozone depletion made by comparing assimilated fields of ENVISAT/MIPAS data to passively transported fields. Vertical transport was implemented in DIAMOND when deriving row (C) but not when deriving row (D). Rows (E) and (F) describe estimates of ozone depletion made using assimilated fields of Odin/SMR data. Vertical transport was implemented in DIAMOND when deriving row $(\mathrm{E})$ but not when deriving row $(\mathrm{F})$. The solid white lines outline the border of the polar vortex. 
Significant differences have been found between estimates of ozone depletion made using data from the ENVISAT/MIPAS and Odin/SMR instruments. In the Antarctic winter of 2003 assimilated fields of ENVISAT/MIPAS data indicated vortex ozone depletion in the ranges $80-100 \%$ and $70-90 \%$ on the 425 and $475 \mathrm{~K}$ levels respectively while Odin/SMR data indicated depletion in the ranges $70-90 \%$ and $50-70 \%$ on the same levels. By comparing the assimilated fields to balloon sondes released at the south pole we have deduced that this discrepancy can be attributed to systematic errors in the Odin/SMR data. See Fig. 8.

Estimates of Arctic ozone depletion on the $475 \mathrm{~K}$ level between 1 January and the end of February are presented in Fig. 12. Using data from ENVISAT/MIPAS we have deduced 10-20\% ozone depletion in the central region of the vortex while we have deduced $20-30 \%$ depletion using data from Odin/SMR.

The rates of ozone depletion in the Arctic winter of 2002/2003 has been studied using the Match method in Streibel et al. (2006) and by obtaining vortex averages of ozone zonde measurements in Christensen et al. (2005). Both papers describe 1.0-1.25 ppmv accumulated vortex ozone losses on the $475 \mathrm{~K}$ level during January and February which corresponds to $\sim 30 \%$ destruction of the vortex ozone on that level. The two studies thus agree with the results we have obtained using Odin/SMR data while the ENVISAT/MIPAS instrument seems to be underestimating the ozone depletion in the Arctic winter of 2002/2003.

Acknowledgements. Odin is a Swedish-led satellite project funded jointly by the Swedish National Space Board (SNSB), the Canadian Space Agency (CSA), the National Technology Agency of Finland (Tekes) and the Centre National d'etudes Spatiales (CNES) in France. We thank the European Space Agency (ESA) for providing ENVISAT/MIPAS data. ECMWF wind and temperature fields have been downloaded from the data centre at Norsk Institutt for LUftforskning (NILU) operated under the EU supported SCOUT project. This work has also been supported by the Chalmers Environmental Initiative (www.miljo.chalmers.se/cei).

Edited by: P. Espy

\section{References}

Christensen, T., Knudsen, B. M., Streibel, M., Andersen, S. B., Benesova, A., Braathen, G. O., Claude, H., Davies, J., De Backer, H., Dier, H., Dorokhov, V., Gerding, M., Gil, M., Henchoz, B., Kelder, H., Kivi, R., Kyrö, E., Litynska, Z., Moore, D., Peters, G., Skrivankova, P., Stübi, R., Turunen, T., Vaughan, G., Viatte, P., Vik, A. F., von der Gathen, P., and Zaitcev, I.: Vortex-averaged Arctic ozone depletion in the winter 2002/2003, Atmos. Chem. Phys., 5, 131-138, 2005,

http://www.atmos-chem-phys.net/5/131/2005/.

Daley, R.: Atmospheric data analysis, Cambridge University Press, 1991.

Endemann, M.: MIPAS instrument concept and performance, Proceedings of the European Symposium on Atmospheric Measure- ments from Space, ISSN 1022-6656 (European Space Research and Technology Center - European Space Agency, Noordwijk, The Netherlands, 1999), WPP-161, Vol. 1, 29-43, 1999.

EORCU: The Northern Hemisphere Stratosphere in the 2002/2003 winter, Tech. rep., The European Ozone Research Coordinating Unit, Department of Chemistry, University of Cambridge, UK, 2003.

Farman, J. C., Gardiner, B. G., and Shanklin, J. D.: Large losses of total ozone in Antarctica reveal seasonal $\mathrm{ClO}_{\mathrm{x}} / \mathrm{NO}_{\mathrm{x}}$ interaction, Nature, 315, 207-210, 1985.

Khattatov, B. V., Lamarque, J.-F., Lyjak, L. V., Menard, R., Levelt, P., Tie, X., Brasseur, G. P., and Gille, J. C.: Assimilation of Satellite Observations of Long-lived Chemical Species in Global Chemistry Transport Models, J. Geophys. Res., 105(D23), 29135, doi:10.1029/2000JD900466, 2000.

Menard, R., Cohn, S. E., Chang, L.-P., and Lyster, P. M.: Stratospheric assimilation of Chemical Tracer Observations Using a Kalman Filter, parts i and ii, Mon. Wea. Rev., 128, 2654-2686, 2000.

Murtagh, D., Frisk, U., Merino, F., Ridal, M., Jonsson, A., Stegman, J., Witt, G., Eriksson, P., Jiménez, C., Megie, G., de la Noë, J., Ricaud, P., Baron, P., Pardo, J. R., Hauchcorne, A., Llewellyn, E. J., Degenstein, D. A., Gattinger, R. L., Lloyd, N. D., Evans, W. F. J., McDade, I. C., Haley, C. S., Sioris, C., von Savigny, C., Solheim, B. H., McConnell, J. C., Strong, K., Richardson, E. H., Leppelmeier, G. W., Auvinen, H., and Oikarinen, L.: An overview of the Odin atmospheric mission, Can. J. Phys., 80, 309-319, 2002.

Newman, P. A., Harris, N. R. P., Adriani, A., Amanatidis, G. T., Anderson, J. G., Braathen, G. O., Brune, W. H., Carslaw, K. S., Craig, M. S., DeCola, P. L., Guirlet, M., Hipskind, R. S., Kurylo, M. J., Küllmann, H., Larsen, N., Megie, G. J., Pommereau, J.-P., Poole, L. R., Schoeberl, M. R., Stroh, F., Toon, O. B., Trepte, C. R., and Roozendael, M. V.: An overview of the SOLVE/THESEO 2000 campaign, J. Geophys. Res., 107(D20), 8259, doi:10.1029/2001JD001303, 2002.

Prather, M. J.: Numerical Advection by Concervaion of SecondOrder Moments, J. Geophys. Res., 91(D6), 6671-6681, 1986.

Proffitt, M. H. K., Aiken, J. J., Margitan, M., Lovenstein, J. R, and Podolske, A.: Ozone loss inside the northern polar vortex during the 1991-1992 winter, Science, 261, 1150-1154, 1993.

Raspollini, P., Bellotti, C., Burgess, A., Carli, B., Carlotti, M., Ceccherini, S., Dinelli, B. M., Dudhia, A., Flaud, J. M., Funke, B., Höpfner, M., Lopez-Puertas, M., Payne, V., Piccolo, C., Remedios, J. J., Ridolfi, M., and Spang, R.: MIPAS level 2 operational analyses, Atmos. Chem. Phys., 6, 5605-5630, 2006, http://www.atmos-chem-phys.net/6/5605/2006/.

Rex, M., von der Gathen, P., Harris, N. R. P., Lucic, D., Knudsen, B. M., Braathen, G. O., Reid, S. J., De Backer, H., Claude, H., Fabian, R., Fast, H., Gil, M., Kyrö, E., Mikkelsen, I. S., Rummukainen, M., Smit, H. G., Stähelin, J., Varotsos, C., and Zaitcev, I.: In situ measurements of stratospheric ozone depletion rates in the Arctic winter 1991/1992: A Lagrangian approach, J. Geophys. Res., 103(D5), 5843, doi:10.1029/97JD03127, 1998.

Ridolfi, M., Carli, B., Carlotti, M., von Clarmann, T., Dinelli, B. M., Dudhia, A., Flaud, J. M., Morris, P. E., Raspollini, P., Stiller, G., and Wells, R. J.: Optimized forward model and retrieval scheme for MIPAS near-real-time data processing, Appl. Opt., 39, 1323$1340,2000$. 
Solomon, S.: Stratospheric ozone depletion: A review of concepts and history, Rev. Geophys., 37, 275-316, doi:10.1029/1999RG900008, 1999.

Streibel, M., Rex, M., von der Gathen, P., Lehmann, R., Harris, N. R. P., Braathen, G. O., Reimer, E., Deckelmann, H., Chipperfield, M., Millard, G., Allaart, M., Andersen, S. B., Claude, H., Davies, J., De Backer, H., Dier, H., Dorokov, V., Fast, H., Gerding, M., Kyrö, E., Litynska, Z., Moore, D., Moran, E., Nagai, T., Nakane, H., Parrondo, C., Skrivankova, P., Stübi, R., Vaughan, G., Viatte, P., and Yushkov, V.: Chemical ozone loss in the Arctic winter 2002/2003 determined with Match, Atmos. Chem. Phys., 6, 2783-2792, 2006, http://www.atmos-chem-phys.net/6/2783/2006/.

Urban, J., Lautie, N., Le Flochmoen, E., Murtagh, D., Ricaud, P., De La Noe, J., Dupuy, E., Drouin, A., El Amraoui, L., Eriksson, P., Frisk, U., Jimenez, C., Kyrola, E., Llewellyn, E. J., Megie, G., Nordh, L., and Olberg, M.: The northern hemisphere stratospheric vortex during the 2002/03 winter: Subsidence, chlorine activation and ozone loss observed by the Odin Sub-Millimetre Radiometer, Geophys. Res. Lett., 31, L07103, doi:10.1029/2003GL019089, 2004.
Urban, J., Lautie, N., Le Flochmoen, E., Jimenez, C., Eriksson, P., De La Noë, J., Dupuy, E., Ekström, M., El Amraoui, L., Frisk, U., Murtagh, D., Olberg, M., and Ricaud, P.: Odin/SMR limb observations of stratospheric trace gases: Level 2 processing of ClO, N2O, HNO3, and O3, J. Geophys. Res., 110, D14307, doi:10.1029/2004JD005741, 2005.

Urban, J., Murtagh, D., Lautié, N., Barret, B., Dupuy, E., de La Noë, J., Eriksson, P., Frisk, U., Jones, A., le Flochmoën, E., Olberg, M., Piccolo, C., Ricaud, P., and Rösevall, J.: Odin/SMR Limb Observations of Trace Gases in the Polar Lower Stratosphere during 2004-2005, Proc. ESA Atmospheric Science Conference, 8-12 May 2006, Frascati, Italy, European Space Agency publications, ESA-SP-628, http://earth.esrin.esa.it/workshops/ atmos2006/participants/68/paper_frascati2006.pdf, 2006. 